This item was submitted to Loughborough's Research Repository by the author.

Items in Figshare are protected by copyright, with all rights reserved, unless otherwise indicated.

\title{
Interpersonal relationships in transnational, virtual teams - towards a configurational perspective
}

PLEASE CITE THE PUBLISHED VERSION

http://dx.doi.org/10.1111/j.1468-2370.2010.00284.x

PUBLISHER

(C) Blackwell Publishing and British Academy of Management / ( ) The author

VERSION

AM (Accepted Manuscript)

LICENCE

CC BY-NC-ND 4.0

\section{REPOSITORY RECORD}

Zimmermann, Angelika. 2019. "Interpersonal Relationships in Transnational, Virtual Teams - Towards a Configurational Perspective”. figshare. https://hdl.handle.net/2134/8171. 
This item was submitted to Loughborough's Institutional Repository (https://dspace.lboro.ac.uk/) by the author and is made available under the following Creative Commons Licence conditions.

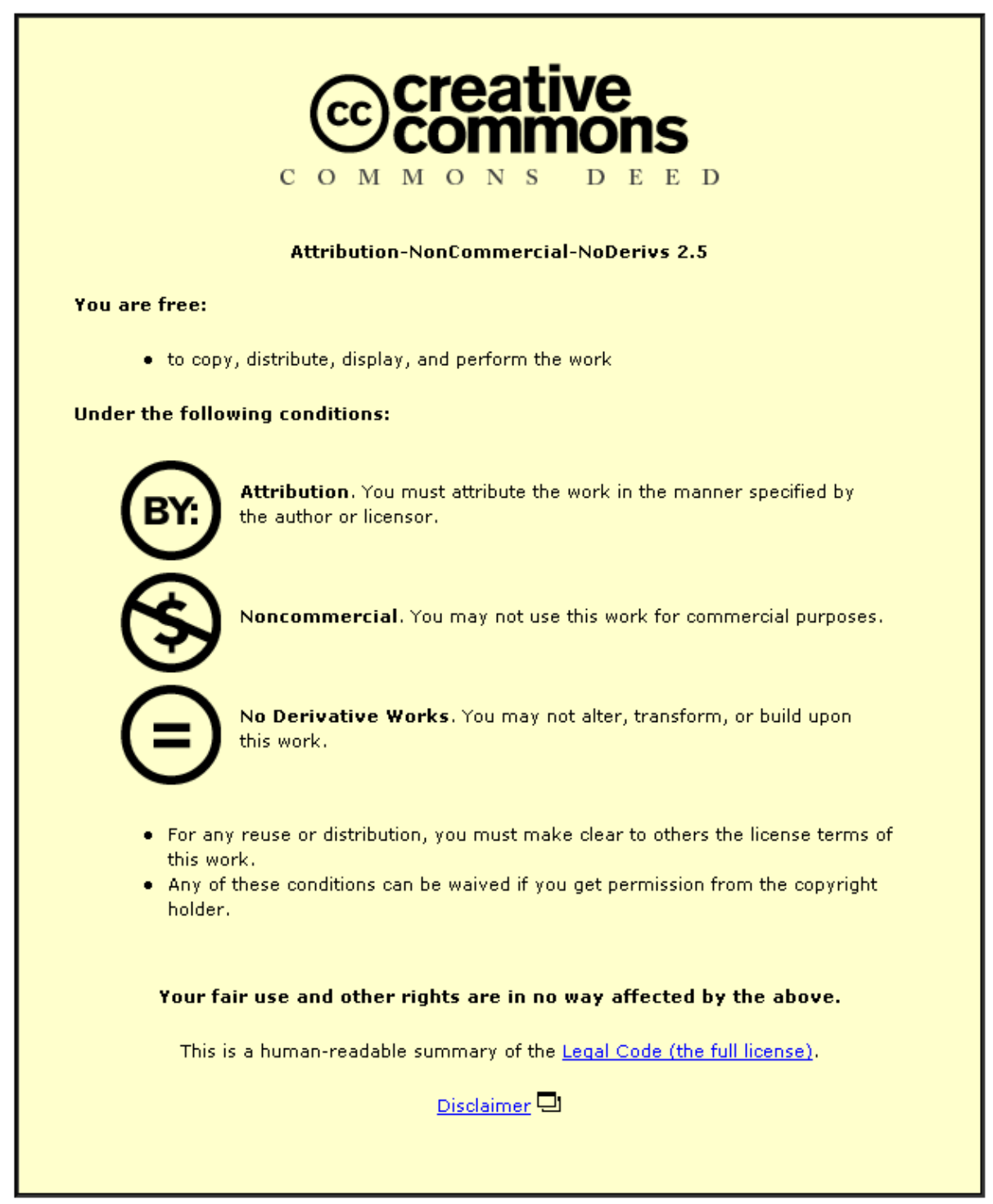

For the full text of this licence, please go to: http://creativecommons.org/licenses/by-nc-nd/2.5/ 
Interpersonal relationships in transnational, virtual teams - towards a configurational perspective

Dr. Angelika Zimmermann*

Lecturer in International Business and Strategy

Loughborough University Business School

Loughborough

LE11 3TU

U.K.

Tel: +44 (0)1509 228845

E-mail: A.Zimmermann@lboro.ac.uk 


\section{Interpersonal relationships in transnational, virtual teams - towards a configurational perspective}

Previous research has observed that strong interpersonal relationships are especially important for the functioning of transnational, virtual teams (TNTs), but are at the same time particularly hard to achieve in these teams. This article reviews and integrates the transnational and virtual team literature to provide an overview of examined cognitive, behavioural, and affective relationship aspects. By demonstrating the interrelations between these relationship aspects, the article deviates from the prevalent, linear inputprocess output models of team functioning and makes a first step towards a configurational perspective on relationships in transnational, virtual teams. It further reviews how several characteristics of the team structure, organisational context, and socio-political environment may facilitate or inhibit relationship aspects. Through a synthesis of previous research, the article develops two examples of likely relationship configurations and their driving factors. The review concludes by recommending methods for future empirical research on relationship configurations in TNTs.

\section{Keywords}

Transnational teams, multinational teams, global teams, virtual teams, configuration, nonlinear systems, relationships 
Over the last decade, research on transnational teams (TNTs) has grown from a small, specialist area into a major stream of interest covering several disciplines. TNTs have been investigated by social psychologists as well as experts on international business and information systems. This has led to the first literature reviews (Berg 2006; Connaughton and Shuffler 2007; Podsiadlowski 2002; Stahl et al. 2009) and an edited book on the subject (Shapiro et al. 2005). Given that TNTs are often geographically dispersed, many TNT studies include issues of virtual collaboration.

Due to the importance of transnational, virtual teams for international organisations, many researchers have focussed on what makes these teams effective. One central, repeated observation is that positive, effective relationships among TNT members are especially important for TNT success, but are at the same time particularly hard to achieve (e.g., Gibbs 2006; Gibson and Manuel 2003; Gluesing and Gibson 2004; Maznevski et al. 2006). On a broad level, interpersonal relationships in TNTs can be defined as the ways in which team members relate to each other. Some researchers have emphasised the importance of interpersonal relationships in TNTs by referring to the encompassing framework of social capital, which highlights the significance of relationships as a resource of social action (Nahapiet and Ghoshal 1998: 242). Others have used the related theory of social networks to characterise the complex, internal and external links of TNT members and the shifting boundaries of TNTs (Joshi et al. 2002; Maznevski and Anthanassiou 2006). Moreover, many studies have singled out particular processes that will here be termed 'aspects' of relationships. Relationship aspects are facets of the ways that TNT members relate to each other, such as trust and communication patterns. Some studies describe interconnections between certain 
relationship aspects, providing reasons to assume that there may be many more, unrevealed interrelations.

What is to date missing is a comprehensive overview of the most significant relationship aspects in TNTs and their interconnections. The present review aims to sketch such a broad picture from what has been examined so far. Previous TNT research will be integrated to identify suggested interrelations between different relationship aspects. Thereby, the review deviates from the prevalent linear Input-Process-Output models of team functioning that follow classic system models (e.g., Hackman and Oldham 1980; McGrath 1984). Instead, it will make a first step towards a non-linear systems analysis and, through this, a configurational perspective on relationships in TNTs. Both of these approaches provide better insights into the complex nature of TNT relationships and therefore provide a better understanding of what makes good working relationships in these teams.

\section{Non-linear systems, configurations}

The non-linear systems approach claims that social systems tend to consist of a multitude of elements that influence each other reciprocally, making it impossible to clearly distinguish cause and effect and predict their pattern in the long term (see Mendenhall 1999, for a review). Nevertheless, post-hoc observations of non-linear system development show that these systems do follow certain patterns, apparently caused by 'deep-order dimensions' within the system itself, which set certain bounds and guide the system's behaviour. These patterns have been termed 'attractors', because they seem to attract system behaviours to follow the pattern (Capra 1996) According to 
Mendenhall (1999), these attractors can in organisations be defined in terms of key success factors.

The configurational perspective, in turn, has been developed in organisational theory (e.g., Meyer, Tsui and Hinings 1993; Miller 1990, 1996). It is influenced by psychological Gestalt research, which demonstrates that individuals perceive objects as configurations and thereby reduce their complexity. Gestalts are typical configurations that are not merely a sum of their elements, but have their own distinctive character. Accordingly, the configurational perspective within organisational theory posits that organisational reality cannot be explained by unidirectional, causal relationships between isolated variables, but only in terms of variable configurations, i.e. 'multidimensional constellations of conceptually distinct characteristics that commonly occur together' (Meyer et al. 1993: 1175). The effect of single variables depends on their interaction with the multitude of other variables in a configuration. Because of this interdependency, variables tend to fall into a limited number of coherent, typical patterns, i.e. configurations that are equivalent to Gestalts. More beneficial configurations, for example regarding organisational success, are characterised by greater congruence between their elements (Miller 1996). Organisational configurations are thought to be formed due to driving ‘forces’ (Meyer et al. 1993: 1176), ‘orchestrating themes’ (Miller, 1996), or ‘imperatives’ (Miller 1987) such as environmental constraints, organisational structure, or leadership, similar to the attractors of nonlinear systems. Typical configurations can be captured either through conceptual typologies or empirically derived taxonomies (Miller 1996). 
With regard to TNTs, attempts to describe typical configurations have so far been made primarily in the practitioner-oriented literature. For example, DiStefano and Maznevski (2000) divide TNTs into three performance clusters, namely 'destroyers' characterised by negative stereotyping and destructive relationships, 'equalisers' who deny differences between team members, and 'creators' who recognise and build on differences.

With regard to virtual teams, which includes TNTs, Bell and Kozlowski (2002) develop a typology along two extreme ends of a continuum, designating different degrees of virtuality. The first extreme type is characterised by multiple member roles, a discrete lifecycle, and temporal distribution. The other extreme type of virtual teams is characterised by the opposite qualities of these dimensions. The position of a virtual team on this continuum depends primarily on two factors, task complexity and work flow patterns. In this review, two examples of theoretically likely configurations of TNT relationships and their determining factors will be proposed, which partly accord with Bell and Kozlowski’s (2002) typology, as discussed in the conclusions.

\section{Definitions and methods for this review}

As Shapiro et al. (2005) point out, disparate terminologies are used to designate (what they term) multinational teams, and this contributes to a lack of integration in the literature. Shapiro et al. urge researchers to explicitly identify the examined aspects of multinational teams and to develop shared definitions, in order to develop consistent measurement tools and accumulate empirical observations. However, as long as a vast variety of terms is used for similar forms of TNTs, it is necessary to include all of these 
in this literature review. The term 'team' is here used broadly to designate a group of people working on a common task. The term 'transnational, virtual teams' was chosen to designate research that focuses on transnational, i.e., international, multinational, multicultural, cross-cultural or global teams which are at the same time virtual, i.e. geographically dispersed or distributed and collaborate with the help of electronic communication media. The label 'transnational' is here regarded as more generic than 'multinational' or 'multicultural', because it comprises teams composed of either many or only two nationalities, and it includes diversity of nationality, rather than only cultural diversity. All of these terms were used for a web based literature search. Both empirical and conceptual papers and book chapters were included when they made a significant contribution to the leading questions.

The literature was classified into a number of different approaches to TNT research. Several researchers have developed comprehensive models of TNT functioning, which commonly adhere to an Input-Process-Output (IPO) structure. They typically distinguish factors, processes, and outcomes and identify mostly linear relationships between them (e.g. Earley and Gardner 2005; Earley and Gibson 2002; Maznevski et al. 2006). Others have developed similarly structured, but more practitioner-oriented models, focussing on the actions that serve to improve transnational teamwork (e.g., Davison and Ward 1999; Gibson and Grubb 2005; Gluesing and Gibson 2004). A number of scholars have investigated particular aspects of relationships in TNTs (e.g., team identity: Shapiro et al. 2002; subgroups: Cramton and Hinds 2005; hybrid culture: Earley and Mosakowski 2000; trust: Jarvenpaa and Leidner 1999; etc.). Each of these studies draws on one or more theoretical frameworks, such as social identity, team faultlines, or social networks. 
By examining on relationship aspects (facets of the ways that TNT members relate to each other), attention is focussed on what is usually examined as part of 'processes' in IPO models. However, this paper covers all three components (I,P, and O) of IPO models, as it considers several factors and performance outcomes of interpersonal relationships. Moreover, whilst the IPO framework typically imposes a 'single-cycle linear path from inputs through outcomes' (Ilgen et al. 2005: 520), this review will demonstrate that many aspects influence each other and can therefore be regarded simultaneously as inputs, processes, and outputs.

Accordingly, Figure 1 illustrates all relationship aspects as part of the same circle, rather than in separate boxes. Figure 2, in turn, depicts influencing factors, i.e. characteristics of the team structure, organisational context, and socio-political context that shape relationships. The factors are depicted as concentric circles around the relationship circle, to emphasise that these factors influence the constellation of interlinked relationship aspects, rather than each relationship aspect separately. Influences on particular aspects are detailed in Appendix 1. To avoid over-complication, TNT performance is not included in the figures.

\section{INSERT FIGURES 1 and 2 ABOUT HERE}

To organise this review of different relationship aspects, the psychological distinction between cognitive, behavioural, and affective relationship aspects is adopted. This framework serves to highlight similarities between the aspects that are situated at the same psychological level. For example, there is an overlap of the cognitive processes involved in team identity, subgroup formation, and shared understanding, whilst communication and knowledge overlap on the behavioural level. However, it will be 
emphasised that none of these aspects can be regarded as purely cognitive, behavioural, or affective. Each aspect also involves other levels.

Relationship aspects prominent in the literature will be presented in the sequence shown in Figure 1. Aspects classified as ‘cognitive', such as team identity and subgroup formation, are discussed first, followed by behavioural aspects including amongst others communication and knowledge creation, before describing affective aspects, namely interpersonal affect and satisfaction. Throughout, I summarise what has been said about the function of these aspects, both with regard to team performance and their influence on other relationship aspects. The next focus will be on cultural diversity and virtuality as the two characteristics of the team structure that have been discussed most frequently and with regard to all relationship aspects. It will become clear how they make effective relationships more important but at the same time often harder to achieve. However, diversity and virtuality can also have certain positive effects on relationship aspects. When discussed in the literature, it is further explained how each relationship aspect relates to a number of other factors apart from virtuality and culture. Within the team structure, team leadership, shared goals, and task interdependence are discussed. The review also includes organisational context and socio-political context factors where mentioned in the literature. To draw conclusions, I highlight the main insights regarding non-linear systems and configurations, develop configuration examples, and make a number of suggestions for future research.

\section{Cognitive aspects of relationships in TNTs}


The most frequently discussed cognitive aspects of relationships in TNTs can be classified as team identity, subgroup formation, role expectations, shared understanding, and trust.

\section{Team identity}

Team identity has been claimed to be a key facet of social capital (Nahapiet and Ghoshal 1998: 244) and is therefore a crucial aspect of relationships in TNTs. Team identity and identification are commonly explained on the basis of social categorisation and social identity theory. Social categorisation theory posits that people form their initial impressions of each other according to social categories (Turner 1987). Social identity theory, in turn, suggests that individuals identify with a group (their 'ingroup') on the basis of their perceived degree of similarity with others, which in turn depends on their social categorisation of self and others (Tajfel 1982).

A TNT can have a stronger or weaker team identity. A strong TNT identity has been described as a 'coupling mechanism’ (Gibbs 2006: 347), and, accordingly, strengthens various relationship aspects. It has been suggested to increase TNT members' mutual trust (Henttonen and Blomqvist 2005; Maznevski et al. 2006; Zakaria et al. 2004) and to motivate members to contribute their knowledge to the TNT (Fulk et al. 2005). Moreover, Hinds and Mortensen (2005) found that team identity moderates the effect of geographic distribution on interpersonal conflicts in TNTs. According to Harvey et al. (2005), identification with the team also motivates TNT members to contribute their effort to the team goal, because it implies that team members perceive their individual goals to be to some degree congruent with the team's goals. 
This function of team identity may be particularly relevant for TNTs when compared to mono-national teams. Shapiro et al. (2002) suggest that TNTs are more likely to suffer effort-withholding behaviour, because cultural diversity limits their socioemotional understanding of each other, and geographic distribution reduces timely assistance and monitoring which would encourage members to contribute effort. Team identity is seen to reduce effort-withholding behaviour despite these constraints, thus acting as a mediator. Despite its particular importance, a strong team identity also appears to be more difficult to achieve in TNTs. For example, Shapiro et al. (2002) suggest that limited socio-emotional understanding due to cultural differences makes it more difficult to achieve team identity. They further reason that team identity formation is restrained by virtuality and reliance on electronic communication media, leading to a lack of visibility of team members' faces and of personal, informal bonding.

\section{Subgroup formation}

Subgroups in teams are typically understood to form along 'faultlines', i.e. hypothetical dividing lines which split a group into subgroups, according to members' shared core attributes (Lau and Murnighan 1998: 328). In TNTs, nationality characteristics are likely to be the salient attributes that act as a basis of subgroup identities (Gibson and Grubb 2006). Accordingly, Joshi et al. (2002) demonstrate that TNT members formed subgroups according to national subsidiaries. TNT members are thus likely to categorise members of other nationalities as part of 'outgroups' (the group they do not identify with), and evaluate them less positively than members of their own national ingroup (Gibson and Grubb 2006: 72). Such subgroup divides tend to form more strongly in moderately 
heterogenous teams (Earley and Mosakowski, 2000), such as those composed of only two nationalities (Hajro, 2009), compared to highly heterogeneous teams.

When examining the relation of subgroup formation with other relationship aspect, it becomes apparent that subgroup formation may have either negative or positive effects. Early and Mosakowski (2000) found that strong faultlines in TNTs were related to low levels of team identity, communication problems, and relational conflict. Gibson and Manuel (2003) suggest that TNT members can lack trust towards members of other national subgroups. In the same vein, Cramton (2001) reports that polarised groups withheld information from each other, which implies limited knowledge creation. However, subgroups are not always detrimental for team functioning and may even have positive effects on other relationship aspects (see Panteli and Davison 2005; Stahl et al. 2009). Gibson and Vermeulen (2003) demonstrated that when subgroups were moderately strong, i.e., a moderate amount of characteristics were shared within the subgroup (e.g., nationality), but a number of other characteristics were shared with members of other subgroups (e.g., profession), then the team maintained an 'inclusive atmosphere’ and subgroups stimulated team learning, a form of knowledge creation. Subgroup strength and dynamics are seen to be dependent on a number of structural factors in TNTs. Super-ordinate, shared team goals can act as a bridging mechanism in TNTs that strengthens shared team identity (e.g., Earley and Gardner 2005; Earley and Gibson 2002; Mcdonough and Cedrone 2000). The team leader can take an important role in stressing similarities of group members across national subgroups, and in emphasising shared group goals (e.g., Davison and Ward 1999). With regard to organisational factors, Hajro (2009) use a case study to demonstrate how effective human 
resource management can foster collective team identification by reducing continuous withdrawal of team members throughout the life span of the TNT.

Moreover, the socio-political context may affect the salience of core member characteristics. For example, political tensions between member countries may highlight nationality membership and reinforce subgroup identities (Jelinek and Wilson 2005).

\section{Role expectations}

In a TNT, expected roles describe team member's assumptions of who should do what with regard to the team's task and member interactions (Sutanto et al. 2005: 2). The importance of clearly defined roles in transnational, virtual teams has been stressed by Earley and Gibson (2002) and Earley and Gardner (2005), describing the effect on other relationship aspects. These authors posit that team members have to be aware of each others' role expectations in order to avoid interpersonal conflict. Matching role expectations are also part of a shared understanding in terms of a hybrid culture (Earley and Mosakowski 2000). A more differentiated perspective is developed by Gibbs (2009), who posits that role ambiguity in TNTs does not need to be eliminated, but should be transcended by balancing contrasting demands.

Sutanto et al. (2005) enlist various role-related difficulties in teams, such as role ambiguity (implying unclear role expectations) and role conflict (two or more incompatible expectations for the behaviour of a person; Sutanto et al. 2005: 2). These conditions are seen to cause stress and lead to detrimental individual roles, such as blockers (who do not contribute effort to the team) and aggressors who cause conflicts. 
The danger of role ambiguity is regarded as particularly high in transnational, virtual teams, due to various structural characteristics. Sutanto et al. (2005) claim that the virtual setting limits communication, which could otherwise reduce role ambiguity. Bell and Kozlowski (2002) suggest that in virtual teams (including TNTs), greater task complexity entails greater task interdependence, which in turn relies on clear role definitions. They further explain that complex tasks require team leaders to overcome role ambiguity by specifying singular, fixed roles to each team member. The reviewed literature did not make any clear observations regarding the influence of the organisational context or socio-political factors on role expectations.

\section{Shared understanding}

It is essential for TNTs to achieve a shared understanding of various team and situation features, due to its effect on other relationship aspects. Shapiro et al. (2002) claim that limited socio-emotional understanding will weaken team identity. Jarvenpaa and Leidner (1999) demonstrate that a shared understanding of social norms reinforces trust. Moreover, shared communication codes, language, narratives (Baba et al. 2004) and awareness of team members' knowledge (Gluesing and Gibson 2004) are seen to be necessary for exchanging information and thereby creating knowledge. Govindarajan and Gupta (2001) suggest that a shared understanding of the TNTs charter, i.e. scope, deliverables, and timeliness, is necessary for achieving member accountability, which is tied to clear role expectations, and their commitment, which implies contribution of effort. In the same vein, Gibson and Grubb (2005) posit that a shared understanding of what constitutes positive contributions helps limit social loafing and increase cross 
national responsiveness, implying increased contribution of effort. Hinds and Mortensen (2005) found that shared context moderates the effect on team member distribution of task-related conflict. Team members' perception of a shared understanding can further create positive affect (Earley and Mosakowski 2000). According to Sutanto et al. (2005), a shared, organised knowledge structure enhances not only social interactions, but also task performance of a TNT. Similarly, Earley and Mosakowski (2000) demonstrated that a 'hybrid culture', which can be described as shared understanding of emergent group norms, facilitated TNT identity, communication, satisfaction, and effectiveness.

As with team identity, TNTs are likely to face greater difficulties in achieving a shared understanding than mono-national teams, due to structural characteristics. Both cultural differences and physical distance tend to create a divergence of team members' perceptions of team and situation aspects (e.g., Gibbs, 2009; Govindarajan and Gupta 2001). Cultural frames of reference will lead to different preconceptions. For example, Dekker, Rutte and Van den Berg (2008) demonstrate that members of different cultures in global virtual teams deemed partly different interaction behaviours to be most critical for team functioning. Accordingly, Burke et al. (2009) point out that members of multicultural teams have to become aware of their different cultural identities in order to develop shared cognitions. Virtual working will further limit TNT members’ understanding of each others' cultural as well as organisational context.

Shared understanding in TNTs is further dependent on team leaders who can, for example, design shared goals (Earley and Mosakowski 2000) and agree a clear team charter (Govindarajan and Gupta 2001). Hajro (2009) further demonstrates how in an Austrian firm a 'task/ achievement'-oriented organisational culture, as opposed to an 
ethnocentric control-oriented 'role' culture, allowed TNT members to develop their own rules and norms of behaviour, which is a prerequisite of developing a hybrid culture. In a multi-company case study, Hajro and Pudelko (2009) found that a geocentric organisational culture, which combines localisation and integration of cultural values and norms, was the most beneficial for developing new TNT cultures. Furthermore, Schweiger, Atamer and Calori (2003) suggest that human resource practices such as rotational assignments and assigned short-term projects can serve to support shared understanding in TNTs.

The reviewed literature did not mention any influence of socio-political factors on shared understanding.

Trust

Trust has received wide attention in the TNT literature. Trust is usually defined on a cognitive level, for example as a 'willingness to be vulnerable to another party irrespective of the trustor's ability to monitor or control that party’ (Rousseau et al. 1998; cited in Earley and Gardner 2005: 11).

Trust among TNT members is important for many other relationship aspects. Gibson and Gibbs (2006) demonstrate that trust supports innovation, hence knowledge creation, in TNTs, by helping to create a safe communication climate where team members are willing to express their ideas openly, communicate informally, and take risks. In the same vein, trust is argued to contribute to the creation of intellectual capital (Nahapiet and Ghoshal 1998). Moreover, trust has been demonstrated to increase TNT members' motivation to contribute their effort to the team (Dirks 1999). Edwards and 
Sridhar (2003) found that trust between team members had a positive influence on the efficiency and effectiveness of global virtual teams, as well as their satisfaction levels.

However, building trust is more difficult in TNTs compared to collocated, mononational teams and may therefore take longer to develop (Gluesing and Gibson 2004; Hambrick et al. 1998). Geographical dispersion and different national and cultural contexts make it more difficult for team members to estimate each others' competence or motivation which could justify trust (Davison and Ekelund 2004). Moreover, cultural and geographical distance make it harder to interpret other team members' responses. For this reason, team members may have a greater fear of each others' reactions (Glusing and Gibson 2004).

Virtual communication places further limitations on trust building. Personal and face to face conversations have been shown to be necessary for building trust in collocated as well as virtual teams (Henttonen and Blomqvist 2005). Conversely, trust is particulary important for overcoming the communication barriers posed by virtuality as well as cultural differences (Gibson and Gibbs 2006).

However, there are voices that question the effects of culture and virtuality on trust building. Jarvenpaa and Leidner (1999) observe a lack of cultural effects in their sample of global virtual teams. They attribute this partly to visible culture characteristics, such as accent and demeanours, being less obvious during virtual communication. Gibson and Manuel (2003), in turn, did demonstrate that TNT members perceived a high risk in sharing information with members of the cultural outgroup. However, the perceived risk levels decreased with the increase of team members' responsiveness (implying effort) which demonstrated their trustworthiness. Researchers have also suggested that TNTs 
can rely upon 'swift trust' (Jarvenpaa and Leidner 1999). Swift trust is based on expectations derived from social categories or stereotypes, rather than familiarity and interpersonal relationships between team members. A number of additional factors of the team structure influence trust in TNT. Team leaders can actively facilitate the development of trust (Davison and Ward 1999; Govindarajan and Gupta 2001; Moe and Smite, 2008). Gibson and Manuel (2003) suggest that trust increases with higher interdependence of team members' tasks and resources, entailing more frequent interactions and greater familiarity, which makes it easier to judge each others' trustworthiness. Earley and Gardner (2005) further claim that interdependence can be increased by shared goals. Organisational and socio-political factors of trust have not received explicit attention.

\section{Behavioural aspects of relationships in TNTs}

The examination of cognitive relationship aspects has demonstrated how each of these influences other relationship aspects. As a result, a number of partly mutual influences between relationship aspects have started to become clear. The picture will now become more complicated in the discussion of the role of behavioural relationship aspects. TNT researchers have paid considerable attention to the following behavioural relationship aspects: Communication, knowledge creation, contribution of effort, and conflicts.

\section{Communication}

Communication is commonly defined in terms of information being transmitted from a sender, who encodes a message, to a receiver, who decodes the message in order to 
understand its meaning. Communication has a crucial impact on various relationship aspects in TNTs. TNT members need to communicate in order to develop a shared understanding about their expectations, rules, etc. (Earley and Mosakowski 2000: 36). As mentioned, communication is also important for building trust. It serves to obtain information about each other, thereby decreasing uncertainties and providing evidence for each others' trustworthiness. Moreover, unsolicited communication can demonstrate benevolence and thereby increases trust (Jarvenpaa et al. 1998). Not surprisingly, successful information sharing is necessary for creating knowledge in TNTs (Adenfelt and Lagerstroem 2008; Adenfelt and Maaninen-Olsson 2009). Spontaneous, informal communication has been found to strengthen shared identity, reduce negative subgroup interactions, and through this, reduce interpersonal and task conflicts in global virtual teams (Hinds and Mortensen 2005). Finally, Stahl et al.’s (2009) meta-analysis of multicultural team research demonstrated an association between effective communication and team performance.

Communication, like other relationship aspects, has been suggested to be more difficult and at the same time more crucial in TNTs compared to mono-national, collocated teams. This is again attributed mainly to cultural differences and virtuality of TNTs. TNT members' different cultural contexts can lead to disparities in communication codes, entailing misunderstandings (Adler 1997; Erez and Earley 1993; Hambrick et al. 1998). At the same time, communication is particularly important for getting to know each other's culture-specific communication norms (DiStefano and Maznevski 2000; Maznevski 1994). 
The virtual team structure places further obvious constraints on communication. Limited information about other team members’ remote national and organisational contexts makes it more difficult to understand each others' implicit messages. Moreover, virtual communication relies on non-synchronous and less rich media which provide less contextual cues and less immediate feedback than face to face communication. In support of this view, Cramton (2001) demonstrated that virtual teams faced difficulties in retaining contextual information, understanding the salience of information, and interpreting the meaning of silence. Conversely, frequent, deep and interactive communication has been suggested to increase the 'perceived proximity' of virtual TNT members, and thus to moderate the effect of virtuality (Wilson et al. 2008). However, the use of written, direct language in e-mails can reduce misunderstandings that are due to social and nonverbal cues or language (Shachaf, 2008). Moreover, Connaughton (2007) points out that not just the amount of communication may be relevant for TNT functioning, but also its process in relation to its content. Accordingly, Maznevski and Chudoba (2000) demonstrate that successful TNTs used strong, regular patterns of communication, matching communication function with form, and adhering to face to face meetings at regular intervals. In the same vein, temporal coordination of communication has been shown to support interaction behaviours in TNTs, leading to improved performance (Massey et al. 2003).

Several other structural team characteristics influence communication. Team leaders can take an important role in facilitating the appropriate form and frequency of communication through team building and creating shared goals (Davison and Ward 1999; Govindarajan and Gupta 2001. Kumar et al. (2004) highlight that organisational 
strategies can help circumvent barriers to communication in globally distributed teams. Companies can control the interdependence between different subsidiaries by using either differentiation strategies (e.g., sequentialising teamwork) to decrease interdependence and communication needs, or integration strategies (e.g., real-time remote interaction) to achieve higher interdependence and communication. Hajro and Pudelko (2009) additionally show that a geocentric organisational culture that combined localisation and integration helped develop effective intercultural communication, whilst a highly centralised organisational culture inhibited cross-cultural communication.

\section{Knowledge creation}

Knowledge creation has received considerable attention as a desirable process and outcome of TNT work. It is often described in terms of team learning. For instance, Zellmer-Bruhn and Gibson (2006: 501) define team learning as the collective acquisition, combination, creation, and sharing of knowledge by teams. Moreover, knowledge is part of intellectual capital, defined by Nahapiet and Ghoshal (1998: 245) as the knowledge and knowing capability of a social collectivity.

Importantly, Nahapiet and Ghoshal posit that intellectual capital is an attribute of a group. As such, it is seen to be embedded in social practices, and is not reducible to the aggregated actions of individuals. It is therefore apparent that knowledge creation can be defined as an aspect of social relationships in TNTs. Accordingly, Fulk et al. (2005) examine knowledge sharing in TNTs in terms of 'transactive memory' (e.g., Wegner 1995), which they define as a network of interconnected people and the transfer of knowledge resources amongst them. 
Whilst knowledge is of course largely cognitive, creating knowledge involves interactive behaviours, in particular exchanging and combining information between team members. For this reason, knowledge creation has in this review been classified as a behavioural relationship aspect.

Knowledge creation has obvious functions for TNTs. TNTs are often set up for the very purpose of creating knowledge by combining a broad array of knowledge and skills (e.g., DiStefano and Maznevski 2000). TNT performance is then assessed in terms of knowledge creation. The importance of knowledge creation or team learning becomes apparent when considering its effect on other relationship aspects. Team learning regarding existing and new norms is required for creating a shared understanding. Successful knowledge creation is also likely to strengthen team members' trust in the team's competence. Accordingly, Zellmer-Bruhn and Gibson (2006) found a positive effect of team learning on the 'quality of interpersonal relations' in TNTs, measured as satisfaction with the team, commitment to the team, and the level of supportiveness present in the team, indicating that team members will contribute more effort to the team.

Like the other relationship aspects in TNTs, knowledge creation is influenced by the cultural diversity and virtuality of TNT members. This influence can be positive, and some authors therefore stress that differences of culture and context should not be equalled out (Earley and Gibson 2002; Janssens and Brett 2006) but embraced (Gibson and Grubb 2005). Accordingly, in their meta-analysis of previous findings, Stahl et al. (2009) demonstrate that cultural diversity supported creativity in multicultural teams.

On the other hand, diversity and dispersion can also pose challenges to knowledge creation in TNT, by restraining relationship aspects that are crucial for knowledge 
creation. Identification with the team is an important motivator for TNT members to share knowledge across national borders (Fulk et al. 2005), but is harder to develop in dispersed conditions. Virtual communication and culture differences also make it harder for TNT members to clarify their role expectations regarding responsibilities for contributing knowledge, and to develop a shared understanding on where knowledge resources are located (Fulk et al. 2005), both of which is necessary for effectively sharing knowledge. Oshri et al. (2008) therefore demonstrate that frequent teleconferences and occasional short visits were necessary for developing a team mental model of 'who knows what' in globally distributed teams. Moreover, over the distance, it is particularly important for team members to trust that knowledge exchange is reciprocal (Zakaria et al. 2004), because contributions are less visible and cannot be monitored (Fulk et al. 2005). Mcdonough and Cedrone (2000) demonstrate a lack of information sharing in common electronic workspace due to a reduced sense of security in TNTs.

Knowledge creation can be influenced by the same factors that affect the other relationship aspects. Shared goals and leadership will shape knowledge creation indirectly, by facilitating trust, communication, etc. Moreover, the development of a transactive memory system relies on interdependence among team members, which is tied to interdependence of tasks as well as organisational subunits (Fulk et al. 2005). Furthermore, Zellmer-Bruhn and Gibson (2006) demonstrate that the organisational strategies of local responsiveness versus global integration affect learning in TNTs. They explain that local responsiveness provides local offices with more independence, which is necessary for initiating new processes and products. Moreover, the allocation of several functions (R\&D, etc.) at the subsidiary leads to interdependence with other subsidiaries 
and hence a need to share perspectives. Hajro and Pudelko (2009) additionally observe that an organisational culture that combined localisation and integration of cultural norms was the most supportive for motivating international team members to contribute their knowledge to the team, and for absorbing local knowledge into the firm.

\section{Contribution of effort}

Contribution of effort refers to team members actively working to make the team successful, and is here regarded as a behavioural relationship aspect. Whether team members contribute effort depends on their motivation to do so. However, given the close ties between motivation and behaviour, these two aspects are here subsumed under the same heading.

TNT members' effort is required with regard to the team's task and performance (Dirks 1999). In addition, Gibson and Grubb (2005: 77) explain that effort in terms of ‘cross national responsiveness' in TNTs, i.e. 'effortful, timely action in response to a request... from someone of a different nationality...' enhances team members' mutual trust. Moreover, openly expressed feelings of motivation may increase interpersonal affect in terms of the attraction to the group (Jarvenpaa and Leidner 1999) and the tendency for agreement, implying fewer destructive conflicts (Gluesing and Gibson 2004).

Cultural differences and virtuality may again restrain TNT members' effort. Reduced socio-emotional understanding due to cultural and geographical distance as well as limited timely assistance and monitoring make individuals' effort less visible and lead to increased social loafing (Shapiro et al. 2002). Moreover, McDonough and Cedrone 
(2000) demonstrate that TNT members tended to be members of several peer networks simultaneously and therefore faced divided loyalties, which could reduce their motivation to contribute effort to a particular TNT.

Leaders of TNTs have an important function in motivating TNT members to contribute effort to the team (Schweiger, Atamer and Calori 2003). Accordingly, Cordery et al. (2009) use a case study to demonstrate that leaders of parallel global virtual teams can have an important function in building team member engagement against the odds of team members' competing role demands at their various locations.

Hajro (2009) demonstrates in her case study that a task-achievement oriented organisational culture where skills and abilities of employees were more important than their hierarchical position in the company created a motivational climate for TNT members, which implies that they were more willing to contribute effort to the team. Conversely, Hajro and Pudelko (2009) observe that the imposition of headquarters’ organisational culture could lead to a 'passivity' in multinational teams, whilst a combination of localisation and integration of norms motivated team members to contribute effort. Other factors within the team structure and the organisational context have not been examined regarding contribution of effort. However, given that TNT members' motivation to contribute effort depends on other relationship aspects, it will be influenced at least indirectly by the factors that affect these other aspects.

\section{Conflicts}

TNT research has examined task and relationship conflict, and, to a lesser extent, process conflict (Mortensen and Hinds 2005; Stahl et al. 2009). Task conflict relates to perceived 
differences in views referring to tasks, often residing at the cognitive level. Relationship conflict is concerned with interpersonal incompatibilities and is typically associated with interpersonal affect, such as tension. Process conflict refers to disagreements about the ways to complete a task.

Relationship conflict has consistently been associated with process losses and decreased performance. This can be explained by the effect of conflicts on other relationship aspects. For example, Earley and Mosakowski (2000) demonstrated that affective conflicts were in TNTs associated with weaker team identity, communication, and shared understanding in terms of a hybrid culture. Effective handling of conflicts has also been shown to be important for developing trust in global virtual teams (Moe and Smite, 2008). Task conflict can, in contrast, have either positive or negative effects, depending on the nature of the task. Constructive conflicts between contrasting views may be necessary to create a shared understanding (Tuckman 1965). Constructive arguments concerning task-related disagreements are seen to lead to more information sharing (part of communication), but may inhibit performance on highly complex tasks (De Dreu and Weingart 2003). Constructive conflicts are therefore be particularly useful for knowledge creation (Earley and Gibson, 2002), particularly in TNTs that are set up to capitalise on diverse knowledge.

A number of researchers have addressed the question whether TNTs face more conflicts than collocated, mono-national teams. Cultural differences and virtuality are again the main distinguishing factors. There are many reasons why cultural differences could increase conflicts in TNTs, but results are inconclusive. Members of different cultures hold different views on what justifies conflict, what can be classified as a 
conflict, and on appropriate ways of dealing with conflicts (Davison and Ekelund 2004). Von Glinow et al. (2004) therefore suggest that emotional conflict is more likely and harder to solve in multicultural teams. In contrast, the meta-analysis of studies on multicultural teams by Stahl et al. (2009) demonstrated that cultural diversity was significantly related to task conflict, but not to relationship and process conflict. Similarly, Elron (1997) found a positive effect of national diversity on issue-based conflict in TNTs. Kankanhalli et al. (2007), in turn, demonstrated that cultural diversity contributed to both task and relationship conflict. Finally, Bounken and Winkler (2010) draw on a case study to suggest a curvi-linear relationship between diversity of cultural values and conflict levels in TNTs. They argue that intermediate cultural value diversity leads to stronger cultural faultlines, which entail more conflict over the distribution of influence and resources.

Geographic distribution can increase conflicts by reinforcing subgroups along national faultlines. Through a social network analysis, Joshi et al. (2002) demonstrate that each conflict in the TNT of their study occurred mainly between subsidiaries. Accordingly, Cramton (2001) demonstrate that TNT members' lack of understanding of each others' context lead to harsh, categorical attributions and therefore increased conflict. Moreover, virtual communication through electronic media can lead to faster conflict escalation, whilst face to face communication can reduce the anxiety related to conflicts in TNTs (Davison and Ekelund 2004). Kankalli et al. (2006) therefore observe that large volumes of electronic communication and lack of immediacy of feedback in global virtual teams contributed to task conflict. 
On the other hand, Montoya-Weiss et al. (2001) suggest that asynchronous, virtual communication can make aggressive emotions less noticeable. Davison and Ekelund (2004) further suggest that virtual communication helps to diffuse conflicts more easily, by allowing TNT members to reflect upon each another's statements before responding, thereby helping to separate task conflict from emotions. They conclude that different channels are suitable depending on the conflict situation.

Conflicts in TNTs are influenced by many of the previously examined factors. Relationship conflicts may be less detrimental when task interdependence is low (Kankahalli et al. 2006). Team leaders can take a role in monitoring conflict (Davison and Ekelund 2004). They can use temporal coordination mechanisms to ensure conflicts are recognised and dealt with at an early stage (Montoya-Weiss et al. 2001). Shared goals, in turn, can help foster team identity and may thereby reduce conflicts (Earley and Mosakowski 2000). Hajro and Pudelko (2009) argue that a lack of localisation of cultural norms and the imposition of a firm's organisational culture on subsidiary members can lead to resistance and internal conflict in TNTs. The effect of the socio-political context on conflicts has not been investigated explicitly.

\section{Affective aspects of relationships in TNTs}

Affective relationship aspects have not been a major focus of TNT research. However, they are mentioned as effects or even components of the aspects that were here classified as cognitive and behavioural. Two affective aspects - interpersonal affect and satisfaction - can be singled out from the literature. They have been related to many of the discussed cognitive and behavioural aspects. 
Interpersonal affect

Interpersonal affect in TNT can be defined as the positive or negative feelings that team members hold towards each other, which includes liking and dislike (Joshi et al. 2002) as well as attraction, attachment, and affection (Jarvenpaa and Leidner 1999). Interpersonal affect is influential for many other relationship aspects.

Interpersonal attraction due to trait similarity is a reason for identifying with a subgroup (e.g., Adler 1997). Positive affect (i.e., positive feelings that team members hold towards each other), as well as conveying attraction and affection by taking the initiative to respond to each other, may fuel a propensity to trust in TNTs (Earley and Mosakowski 2000: 27; Jarvenpaa and Leidner 1999: 811). Building affective ties promotes contribution of effort in terms of cross national responsiveness and reduced social loafing (Gibson and Grubb 2005). Negative affect, including tension, friction, dislike, and annoyance, are defining symptoms of affective conflict (e.g., Mortensen and Hinds 2005), making it hard to distinguish whether negative affect causes or results from affective conflict. Furthermore, Joshi et al. (2002) demonstrate that 'negative affective networks' influenced performance in TNTs, and had the maximum effect on performance if they overlapped with communication and workflow networks.

Positive affective ties may be more difficult to achieve in conditions of cultural diversity and virtuality. Adler (1997) suggests that multinational team members are likely to be less attracted to members of the national outgroup and will therefore develop more dislike. Both cultural differences and virtual collaboration are also likely to inhibit positive affect indirectly, through their influence on other relationship aspects. Whilst 
other factors within the TNT structure and the organisational context have not been examined with regard to interpersonal affect, Jelinek and Wilson (2005) as well as Hambrick et al. (1998) point out that features of the socio-political context, namely the historical and current relationships (e.g., animosities) between countries may cause certain affect (e.g., tension) between individuals, regardless of their cultural distance.

\section{Satisfaction}

Satisfaction has been defined as team members' affective well-being with respect to team member interactions or team performance (Stahl et al. 2009). Satisfaction has been examined mostly as an outcome of TNT processes, rather than an antecedent. However, it is likely that satisfaction with the team influences other relationship aspects. Satisfaction is likely to lead TNT members to identify more strongly with the team (a stronger team identity), communicate more often, deal with conflicts better, and develop more positive interpersonal affect. With regard to teams that are diverse in observable attributes, including nationality, Milliken and Martins (1996) suggest that satisfaction influences team members' willingness to contribute effort and ideas (which relates to knowledge creation).

Interestingly, both Podsiadlowski’s (2002) and Stahl et al.’s (2009) literature reviews demonstrate a positive relationship between cultural diversity and satisfaction in multicultural teams. Stahl et al. suggest that this may be due to the rewarding experience of intercultural learning. In the same vein, Cramton (2005) suggest that TNT work provides an intercultural learning opportunity which, if taken, can be satisfying. This is in contrast to Milliken and Martins (1996) observation that diversity on observable 
attributes, including national diversity, is likely to lead to lower identification and thereby lower satisfaction with the group. Apparently, cultural differences can entail lower satisfaction and impede relationships in cases where they are not managed well. Earley and Mosakowski (2000) demonstrate that communication and conflict mediate the relationship between national heterogeneity and satisfaction.

Virtuality, in terms of communication over distance and through electronic media, may similarly be an obstacle to satisfaction. Geister and Konradt (2006) suggest that virtual communication decreases satisfaction by limiting the amount of feedback on motivation, task achievement, and relationship related aspects. Accordingly, they were able to demonstrate that online feedback systems improved virtual team member satisfaction. In the same vein, Warkentin, Sayeed and Hightower (1997) demonstrate that virtual teams communicating through an electronic bulletin board system achieved lower satisfaction with the team's work compared to non-virtual teams.

There appears to be no research on the influence of other factors within the team structure or organisational context on satisfaction in TNTs. Nevertheless, these factors are likely to influence satisfaction through their impact on the other relationship aspects.

\section{Conclusions}

\section{Nonlinear systems and configurations in TNTs}

This review has provided an overview of the examined complex interrelations between relationship aspects in TNTs. The matrix in Table 1 aims to clarify this picture. The matrix of Table 1 is confined to the suggestions made in the reviewed literature and can 
therefore only provide an indication of existing interrelations. In the reviewed literature, influences in one direction or the other were suggested for the majority of combinations of aspects. Moreover, mutual influences with other aspects were shown for team identity, subgroup formation, shared understanding, trust, communication, knowledge creation, conflicts, interpersonal affect, and satisfaction. Many more interrelations are likely to exist, especially with regard to role expectations, contribution of effort, and satisfaction, which have so far received less attention.

\section{INSERT TABLE 1 ABOUT HERE}

By demonstrating complex interrelations and several mutual influences between an integrated set of relationship aspects, this review has followed the approaches of nonlinear systems and configurations. As mentioned in the introduction, the non-linear systems view claims that social systems tend to consist of a multitude of elements that influence each other reciprocally, making it impossible to clearly distinguish cause and effect (Mendenhall, 1999). In this review, certain influences between different relationship aspects had to be isolated in order to allow for a clearer analysis, rather than analysing more complex interaction effects. It was thereby possible to suggest certain cause and effect relations theoretically. However, the array of mutual influences suggests that in practice it may not be possible to distinguish cause and effect.

By describing how each relationship aspect influences and is influenced by other aspects, this review further suggested that relationship aspects in TNTs follow non-linear patterns. These patterns are likely to represent typical configurations. Parts of potential configurations were here demonstrated on the basis of previous research. In particular, it was shown how effective communication is likely to occur in combination with a 
stronger team identity, clearer role expectations, increased trust, shared understanding, knowledge creation, conflicts, interpersonal affect, and satisfaction (see Table 1). Each of these aspects will cause others, leading to several combined and interaction effects.

Different kinds of positive as well as negative relationship configurations are likely, as certain relationship aspects can have either positive or negative effects on other aspects, depending on the overall configuration. For example, strong subgroups may either lead to ethnocentrism and conflicts, or to team learning. Virtual communication can lead to either misunderstandings or clarification of language difficulties and avoidance of emotional conflict. Conflicts may either impede knowledge sharing or lead to creation of new knowledge, depending on other relationship characteristics. A synopsis of relationship aspects and their interactions is therefore necessary in order to suggest typical configurations.

The key factors within the team structure, organisation and socio-political content which were identified specifically for TNTs may be regarded as the driving forces that shape particular relationship configurations in TNTs. Cultural differences and virtuality can constrain all relationship aspects, but can under certain conditions support knowledge creation, satisfaction, and conflict diffusion. The TNT literature further suggests that an appropriate combination of structural team characteristics regarding leadership, shared goals, and task interdependence are crucial for relationships in TNTs. There is also some evidence for the influence of organisational context factors on relationships in TNTs, namely the interdependence between organisational subunits, localisation and integration strategies, organisational culture, and human resource practices. Only a few studies indicate that the socio-political context, in particular relationships between countries, 
makes a difference. More empirical research is needed to examine the influence of these factors on other relationship aspects, and to establish whether certain factor configurations are related to more or less beneficial relationship configurations, constituting typical factor-relationship configurations.

From this review, it is possible to suggest typical factor-relationship configurations under consideration of the more frequently examined factors, i.e. factors within the team structure. These are cultural diversity, virtuality, task interdependence, team leadership, and shared goals. Based on a synthesis of the reviewed research, two possible configurations are suggested. These two configurations were chosen to demonstrate that positive relationships can be achieved by different constellations of relationship aspects, depending on the overall configuration of factors and relationship aspects. The focus is thus on the ambiguous effects outlined in the literature. Two orchestrating themes were identified: 'commitment and tight coupling' and 'commitment and loose coupling' (Table 2).

Configuration 1 is characterised by the orchestrating theme of 'commitment and tight coupling'. Relationships in this configuration are positive, because the potential negative effects of strong cultural differences and virtuality are reduced despite high task interdependence, through integrative team leadership, using shared goals. Configuration 2 follows the orchestrating theme of 'commitment and loose coupling'. Cultural differences and virtuality are strong, and integrative leadership is weak. Nevertheless, the TNT's relationships function well, because the team has strong shared goals, and relationships are less relevant due to low task interdependence. 
Subgroup formation is moderate in configuration 1 and supports team learning, as the integrative leader fosters an inclusive atmosphere (Gibson and Vermeulen 2003) and a strong team identity. In configuration 2, subgroups are strong, but the shared goals support a strong team identity and thereby help circumvent the potential negative effects of subgroups, even though integrative leadership is weak. The subgroups can thus arrive at sufficiently effective communication with each other and avoid relational conflicts (Earley and Mosakowski 2000). Team learning will occur rather within the local subgroups than the whole team (Zellmer-Bruhn and Gibson 2006).

In configuration 1 , the close cooperation and frequent communication required by task interdependence, as well as the integrative leader, will help achieve a shared understanding of roles and norms and develop a hybrid culture, leading to effective communication and high levels of trust. In configuration 2, shared understanding and role clarity may be weaker, leading to less effective communication and possibly lower trust (see Kumar et al. 2004), which can impede knowledge creation. However, the shared goals and strong team identity will motivate team members to exchange sufficient knowledge between subgroups where necessary.

Contribution of effort to the team goals will be high in both configurations. In the first, it will be motivated more strongly by personal affective ties and trust (Gibson and Grubb 2005), whilst in configuration 2, shared goals and team identity (see Shapiro et al. 2002) may be the most important reason for contributing effort.

Conflicts are likely to be constructive in both configurations, given the strong team identity and shared goals. In configuration 1, the high levels trust and shared understanding will additionally serve to solve conflicts, whilst relationship conflicts will 
be less detrimental in configuration 2, given the low task interdependence (Kankahalli et al. 2006).

Interpersonal affect, positive and negative, is likely to be more developed in configuration 1, due to weaker subgroups, stronger communication and understanding, and better personal acquaintance through close cooperation with interdependent tasks. This will further affect trust, knowledge creation, conflicts, and contribution of effort. Satisfaction with the team will be high in both configurations, given the positive relationships and their effect on performance chances.

From these two examples, several other configurations can be inferred, such as a configuration of strong cultural diversity and virtuality in combination with weak leadership and goals as well as high interdependence, likely to trigger several negative relationship dynamics.

Interestingly, the second configuration example accords with Gibbs’ (2009) finding that 'dialectical tensions' in a global software team were not detrimental to team interactions, as long as the tensions were managed and negotiated well. Configuration 2 suggests that, instead of aiming at the highest possible degree of integration, it is possible to achieve effective interpersonal relationships despite strong subgroups, less clear role expectations, and incomplete shared understanding. This accords with findings by Zimmermann (2008) and Zimmermann and Sparrow (2007), who demonstrate that TNTs worked effectively by balancing integration and differentiation of interaction styles and work practices.

The two configuration examples further recall important dimensions of Bell and Kozlowski's (2002) typology of virtual teams. These authors state that with less complex 
tasks, work flow will be more additive (i.e., tasks less interdependent). In this case, integration and collaboration are seen to be less crucial to the team's success.

Accordingly, team members can have multiple, less defined and fixed roles (p.30), and communication does not need to be as rich and synchronous. The main difference of the present examples to Bell and Kozlowski’s typology consists in the present focus on a broader range of relationship aspects and on different kinds of positive configurations, rather than extreme types.

\section{Research agenda}

Previous research has singled out particular relationship aspects within TNTs to conduct theoretical and empirical analyses. Typically, these relationships aspects are framed as part of the 'process' element of IPO models. By contrast, this review suggests that future research should include a broader array of relationship aspects and factors, to systematically identify more comprehensive configurations of both relationship aspects and factors, and their association with each other. This would not render former IPO models invalid, but would demonstrate the degree to which they simplify the complex, larger picture. IPO models risk missing crucial interaction effects, but they allow for a simplification that helps examine the mechanisms of influences between certain relationship aspects in more depth. Results from such analyses can be used to inform more holistic, but typically less detailed, configuration research.

For practitioners, such an overview of relationship and factor configurations could provide valuable recommendations on sets of management practices that can support positive relationship configurations under particular structural and organisational 
conditions. Focusing only on a few variables in isolation, such as those mentioned in previous research, may not be sufficient for achieving effective TNT relationships, given the interactions with other elements of a configuration.

Research on typical configurations would have to use a wider empirical lens than most previous studies. In order to establish configurations, it would be necessary to include a more comprehensive range of relationship aspects across a number of different team structures and organisational contexts, and in different socio-political environments. In-depth, qualitative case research would be the most suitable to explore this complex social phenomenon, allowing for rich descriptions and explanations of various relationship configurations and their dependence on factor configurations in specific team structures, organisational contexts, and socio-political contexts. Comparative, multiple case studies of different teams and companies would be particularly useful for highlighting the structural and context influences. Real life organisations are the suitable context for revealing existing configurations. Field experiments, in turn, which do not eliminate the rich real-life context, could be set up to systematically investigate configurations and consolidate previous findings. Such cross-level research implies that data should be collected at the level of individuals (e.g., through interviews) as well as teams (observation of team meetings and e-mail correspondence) and the organisation (analysis of strategy documents and organisational charts). Longitudinal research would be preferable, as relationship aspects may develop and influence each other over time. This would also allow for examining whether incremental changes will at some point lead to a qualitative change and a switch from one configuration to another, as suggested by configuration theorists (Meyer et al. 1993; Miller 1990). Hopefully, the presented 
literature review can provide a conceptual source for such configurational analyses of relationships in TNTs.

\section{References}

Adenfelt, M. and Lagerstroem, K. (2008). The development and sharing of knowledge by centres of excellence and transnational teams: A conceptual framework. Management International Review, 48(3), 319-338.

Adenfelt, M and Maaninen-Olsson, E (2009). Knowledge integration in a multinational setting - a study of a transnational business project. International Journal of Knowledge Management Studies, 3(3-4), 295-312.

Adler, N.J. (1997). International Dimensions of Organizational Behavior, $3^{\text {rd }}$ ed. Cincinnati: South-Western College Publishing.

Baba, M.L., Gluesing, J., Ratner, H. and Wagner, K.H. (2004). The contexts of knowing: natural history of a globally distributed team. Journal of Organizational Behavior, 25, 547-587.

Bell, B.S. and Kozlowski, S.W.J. (2002). A typology of virtual teams: Implications for effective leadership. Group and Organization Management, 21(1), 14-49. 
Berg., N. (2006). Globale Teams: Eine kritische Analyse des gegenwaertigen Forschungsstandes. Zeitschrift fuer Personalforschung, 20(3), 215-232.

Bounken, R. and Winkler, V.A. (2010). National and cultural diversity in transnational innovation teams. Technology Analysis \& Strategic Management, 22(2), 133-151.

Burke, C.S., Priest, H.A., Wooten, S.A., DiazGranados, D. and Salas, E. (2009) Understanding the cognitive processes in adaptive multicultural teams: A framework. In Salas, E., Goodwin, G.F. and Burke, C.S. (eds.), Team Effectiveness in Complex Organizations. New York: Routledge, 209-240.

Capra, F. (1996). The Web of Life. New York: Anchor Books.

Connaughton, S.L. and Shuffler, M. (2007). Multinational and multicultural teams. A review and future agenda. Small Group Research, 38(3), 387-412.

Cordery, J, Soo, C, Kirkman, B., Rosen, B. and Mthieu, J. (2009). Leading parallel global virtual teams: Lessons from Alcoa. Organizational Dynamics, 38(3), 204-216.

Cramton, C. D. (2001). The mutual knowledge problem and its consequences for dispersed collaboration. Organization Science, 12(3), 346-371. 
Cramton, C.D. and Hinds, P. (2005). Subgroup dynamics in internationally distributed teams. Ethnocentrism or cross-national learning? Research in Organizational Behavior, 26, 231-263.

Davison, S.C. and Ekelund, B.Z. (2004). Effective team process for global teams. In Lane, H.W., Maznevski, M.L., Mendenhall, M.L. and McNett, J. (eds.), Handbook of Global Management. A Guide to Managing Complexity. Oxford: Blackwell, 227-249.

Davison, S.C. and Ward, K. (1999). Leading International Teams. London: McGraw Hill.

De Dreu, C.K. and Weingart, L.R. (2003). Task versus relationship conflict and team effectiveness. A meta-analysis. Journal of Applied Psychology, 88, 741-749.

Dekker, D.M., Rutte, S.G. and Van den Berg, P.T. (2008). Cultural differences in the perception of critical interaction behaviors in global virtual teams. International Journal of Intercultural Relations, 32, 441-452.

Dirks, K.T. (1999). The effects of interpersonal trust on work group performance. Journal of Applied Psychology, 84, 445-455.

DiStefano, J. and Maznevski, M.L. (2000) Creating value with diverse teams in global management. Organizational Dynamics, 29(1), 45-63. 
Earley, P.C. and Gardner, H.K. (2005). Internal dynamics and cultural intelligence in multinational teams. In Shapiro, D.L., Von Glinow, M.A. and Cheng, J.L. (eds.), Managing Multinational Teams: Global Perspectives. Oxford, United Kingdom: Elsevier/JAI Press, 1-32.

Earley, C. and Gibson, C.B. (2002). Multinational Work teams. A New Perspective. Mahwah, NJ: L.Erlbaum.

Earley, P.C. and Mosakowski, E. (2000). Creating Hybrid Team Cultures: An Empirical Test of Transnational Team Functioning. Academy of Management Journal, 43(1), 26-49.

Edwards, H.K. and Sridhar, V. (2003). Analysis of the effectiveness of global virtual teams in software engineering projects. Proceedings of the $36^{\text {th }}$ Hawaii international conference on system sciences, IEEE Computer Society Press.

Elron, E. (1997). Top management teams within multinational corporations: Effects of cultural heterogeneity. Leadership Quarterly, 8, 393-412.

Erez, M. and Earley, P.C. (1993). Culture, Self-identity, and Work. New York: Oxford University Press. 
Fulk, J., Monge, P. and Hollingshead, A.B. (2005). Knowledge resource sharing in dispersed multinational teams: three theoretical lenses. In Shapiro, D.L., Von Glinow, M.A. and Cheng, J.L. (eds.), Managing Multinational Teams: Global Perspectives. Oxford, United Kingdom: Elsevier/JAI Press, 155-188.

Geister, S. and Konradt, U. (2006). Effects of Process Feedback on Motivation, Satisfaction, and Performance in Virtual Teams. Small Group Research, 37(5), 459-489.

Gibbs, J.L. (2006). Decoupling and coupling in global teams: implications for human resource management. In Stahl, G.K. and Bjorkman, I. (eds.), Handbook of Research in International Human Resource Management. Cheltenham: Edward Elgar, 347-363.

Gibbs, J.L. (2009). Dialectics in a global software team: Negotiating tensions across time, space, and culture. Human Relations, 62(6), 905-935.

Gibson, C.B. and Gibbs, J.L. (2006). Unpacking the concept of virtuality: The effects of geographic dispersion, electronic dependence, dynamic structure, and national diversity on team innovation. Administrative Science Quarterly, 51, 451-495.

Gibson, C.B. and Grubb, A.R. (2005). Turning the tide in multinational teams. In Shapiro, D.L., Von Glinow, M.A. and Cheng, J.L. (eds.), Managing Multinational Teams: Global Perspectives. Oxford, United Kingdom: Elsevier/JAI Press, 69-96. 
Gibson, C.B. and Manuel, J.A. (2003). Building Trust. In Gibson, C.B. and Cohen, S.G. (eds.), Virtual Teams that Work. San Francisco, Jossey-Bass, 59-86.

Gibson, C.B. and Vermeulen, F. (2003). A healthy divide: Subgroups as a stimulus for team learning behavior. Administrative Science Quarterly, 48(2), 202-239.

Gluesing, J.C. and Gibson, C.B. (2004). Designing and forming global teams. In Lane, H.W., Maznevski, M.L., Mendenhall, M.L. and McNett, J. (eds.), Handbook of Global Management. A Guide to Managing Complexity. Oxford: Blackwell, 199-226.

Hackman, J.R. and Oldham, G.R. (1980). Work Redesign. Reading, MA: AddisonWesley.

Hajro, A. (2009). Contextual influences on multinational teams: empirical evidence from an Austrian company. European Journal of International Management, 3(1), 111-129.

Hajro, A. and Pudelko, M. (2009). Multinational teams in the context of organizational culture: A multi-company case study. In G.T. Solomon (ed.), Academy of Management: Best Paper Proceedings.

Hambrick, D.C., Davison, S.C., Snell, S.A. and Snow, C.C. (1998). When groups consist of multiple nationalities: Towards a new understanding of the implications. Organization Studies, 19(2), 181-205. 
Harvey, M., Novicevic, M. and Garrison, G. (2005). Global virtual teams: A human resource capital architecture. The International Journal of Human Resource Management, 16(9), 1583-1599.

Henttonen, K. and Blomqvist, K. (2004). Managing distance in a global virtual team: The evolution of trust through technology-mediated relational communication. Strategic Change, 14, 107-119.

Hinds, P.J. and Mortensen, M. (2005). Understanding conflict in geographically distributed teams: The moderating effect of shared identity, shared context, and spontaneous communication. Organization Science, 16(3), 290-307.

Ilgen, D.R., Hollenbeck, J.R., Johnson, M. and Jundt, D. (2005). Teams in organizations: From input-process-output models to IMOI models. Annual Review of Psychology, 56, 517-543.

Janssens, M. and Brett, J.M. (2006). Cultural intelligence in global teams. A fusion model of collaboration. Group and Organization Management, 31(1), 124-153.

Jarvenpaa, S.L. and Leidner, D.E. (1999). Communication and trust in global virtual teams. Organization Science, 10(6), 791-815. 
Jarvenpaa, S.L., Knoll, D.E. and Leidner, D.E. (1998). Is anybody out there? The implications of trust in global virtual teams. Journal of Management Information Systems, 14(4), 29-64.

Jelinek, M. and Wilson, J. (2005). Macro influences on multicultural teams: a multi-level view. In Shapiro, D.L., Von Glinow, M.A. and Cheng, J.L. (eds.), Managing Multinational Teams: Global Perspectives. Oxford, United Kingdom: Elsevier/JAI Press, 209-232.

Joshi, A., Labianca, G. and Caligiuri, P. (2002). Getting along long distance: Understanding conflict in a multinational team through network analysis. Journal of World Business, 27, 227-284.

Kankanhalli, A., Tan, B. and Wei, K.K. (2007). 'Conflict and performance in global virtual teams. Journal of Management Information Systems, 23(3), 237-274.

Kumar, K., Van Fenema, P.C. and Von Glinow, M.A. (2005). Intense collaboration in globally distributed work teams: Evolving patterns of dependencies ad coordination. In Shapiro, D.L., Von Glinow, M.A. and Cheng, J.L. (eds.), Managing Multinational Teams: Global Perspectives. Oxford, United Kingdom: Elsevier/JAI Press, 125-154. 
Lau, D.C. and Murnighan, J.K. (1998) Demographic diversity and faultiness: The compositional dynamics of organizational groups. The Academy of Management Review, 23, 325-340.

Massey, A.P., Montoya-Weiss, M.M. and Song, Y.T. (2003). Because time matters: Temporal coordination in global virtual project teams. Journal of Management Information Systems, 19(4), 129-155.

Maznevski, M.L. (1994). Understanding our differences: Performance in decisionmaking groups with diverse members. Human Relations, 47, 531-552.

Maznevski, M.L. and Athanassiou, N.A. (2006). Guest editors' introduction to the focussed issue: A new direction for global teams research. Management International Review, 46(6), 631-646.

Maznevki, M.L and Chudoba, K. (2000). Bridging space over time: Global virtual team dynamics and effectiveness. Organization Science, 11(5), 473-492.

Maznevski, M.L., Davison, S. C. and Jonsen, K. (2006). Global virtual team dynamics and effectiveness. In Stahl, G.K. and Bjorkman, I. (eds.), Handbook of Research in International Human Resource Management. Cheltenham: Edward Elgar, 354-384. 
Milliken, F. J. and Martins, L.L. (1996). Searching for common threads: Understanding the multiple effects of diversity in organizational groups. Academy of Management Review, 21(2), 402-433.

McDonough, E.F. and Cedrone, D. (2000). Meeting the challenge of dispersed team management. Research Technology Management, July-August, 12-17.

McGrath, J.E. (1984). Groups: Interaction and Performance. Englewood Cliffs, NJ: Prentice-Hall.

Mendenhall, M.E. (1999). On the need for a paradigmatic integration in international human resource management. Management International Review, 3, 65-87.

Meyer, A.D., Tsui, A.S. and Hinings, C.R. (1993). Configurational approaches to organizational analysis. Academy of Management Journal, 36(6), 1175-1195.

Miller, D. (1987). The genesis of configuration. Academy of Management Review, 12(4), 686-701.

Miller, D. (1990). Organizational configurations: cohesion, change, and prediction. Human Relations, 43(8), 771-789.

Miller, D. (1996). Configurations revisited. Strategic Management Journal, 17, 505-512. 
Moe, N.B. and Smite, D. (2008). Understanding a lack of trust in global software teams: A multiple-case study. Software Process Improvement and Practice, 13, 217-231

Montoya-Weiss, M.M., Massey, A.P. and Song, M. (2001). Getting it together: temporal coordination and conflict management in global virtual teams. Academy of Management Journal, 44(6), 1251-1262.

Mortensen, M. and Hinds, P.J. (2001). Conflict and shared identity in geographically distributed teams. International Journal of Conflict Management, 12(3), 212-238.

Nahapiet, J. and Ghoshal, S. (1998). Social capital, intellectual capital, and the organizational advantage. The Academy of Management Review, 23(2), 242-226.

Oshri, I., Fenema, P. and Kotlarsky, J. (2008). Knowledge transfer in globally distributed teams: the role of transactive memory. Information Systems Journal, March, 1-24.

Panteli, N. and Davison, R. (2005). The role of subgroups in the communication patterns of global virtual teams. IEEE Transactions on Professional Communication, 48(2), 191200. 
Podsiadlowski, A. (2002). Multicultural Workgoups: A differentiated view on group heterogeneity with regard to design and type of diversity. Zeitschrift fuer Sozialpsychologie, 33(4), 241-259.

Rousseau, D.M., Sitkin, S.B., Burt, R.S. and Camerer, C. (1998). Not so different after all: A cross-discipline view of trust. Academy of Management Review, 23(3), 393-404.

Schweiger, D., Atamer, T. and Calori, R. (2003). Transnational project teams and networks: making the multinational organization more effective. Journal of World Business, 38, 127-140.

Shachaf. P. (2008). Cultural diversity and information and communication technology impacts on global virtual teams: An exploratory study. Information \& Management, 45,131-142.

Shapiro, D.L., Furst, S.A., Spreitzer, G.M. and Von Glinow, M.A. (2002). Transnational teams in the electronic age: Are team identity and high performance at risk? Journal of Organizational Behavior, 23, 455-467.

Shapiro, D.L., Von Glinow, M.A. and Cheng, J.L. (2005). Managing Multinational Teams: Global Perspectives. Oxford, United Kingdom: Elsevier/JAI Press.

Stahl, G., Maznevski, M.L., Voigt, A., \& Jonsen, K. (2009). Unravelling the effects of 
cultural diversity in teams: A meta-analysis of research on multicultural work groups, Journal of International Business Studies, 1-20.

Sutanto, J., Phang, C.W., Kuan, H.H., Kankahalli, A. and Tan, B.C. (2005). Vicious and virtuous cycles in global virtual team role coordination. Proceedings of the $38^{\text {th }}$ Hawaii international conference on system sciences, IEEE Computer Society Press.

Tajfel, H.H. (1982). Social Identity and Intergroup Relations. Cambridge, UK: Cambridge University Press.

Tuckman, B. (1965). Developmental sequence in small groups. Psychological Bulletin, 63, 384-399.

Turner, J.C. (1987). Rediscovering the Social Group: A Self-Categorization Theory. Oxford: Blackwell.

Von Glinow, M.A., Shapiro, D.L. and Brett, J.M. (2004). Can we talk, and should we? Managing emotional conflict in multicultural teams. Academy of Management Review, 29(4), 578-592.

Warkentin, M.E., Sayeed, L. and Hightower, R. (1997). Virtual teams versus face-to-face teams: An exploratory study of a web-based conference system. Decision Sciences, 28(4), 975-987. 
Wegner, D.M. (1995). A computer network model of human transactive memory. Social Cognition, 13, 319-339.

Wilson, J.M., O’Leary, M.B., Metiu, A. and Jett, Q.R. (2008). Perceived proximity in virtual work. Explaining the paradox of 'far-but close'. Organization Studies, 29(7), 9791002.

Zakaria, N., Amelinckx, A., and Wilemon, D. (2004). Working together apart? Building a knowledge-sharing culture for global virtual teams. Creativity and Innovation Management, 13(1), 15-29.

Zellmer-Bruhn, M. and Gibson, C. (2006). Multinational organization context: Implications for team learning and performance. Academy of Management Journal, 49(3), 501-518.

Zimmermann, A. (2008) Mutual Adjustment in International Teams. Saarbruecken: VDM Verlag.

Zimmermann, A., and Sparrow, P.R. (2007). Mutual adjustment processes in international teams: Lessons for the study of expatriation. International Studies in Management and Organization, 37(3), 65-88. 
Figure 1. Relationship Aspects

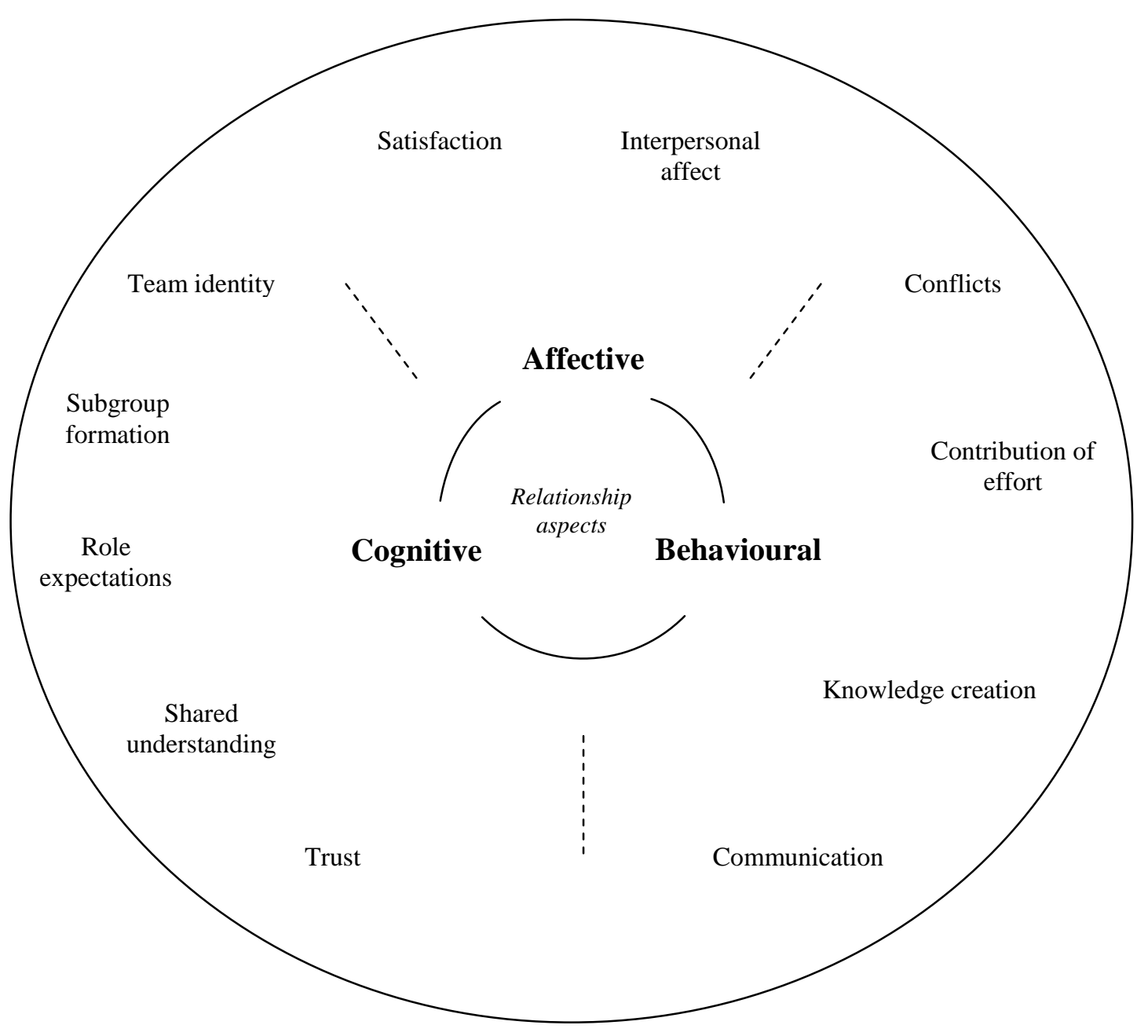


Figure 2. Relationship Aspects and Factors

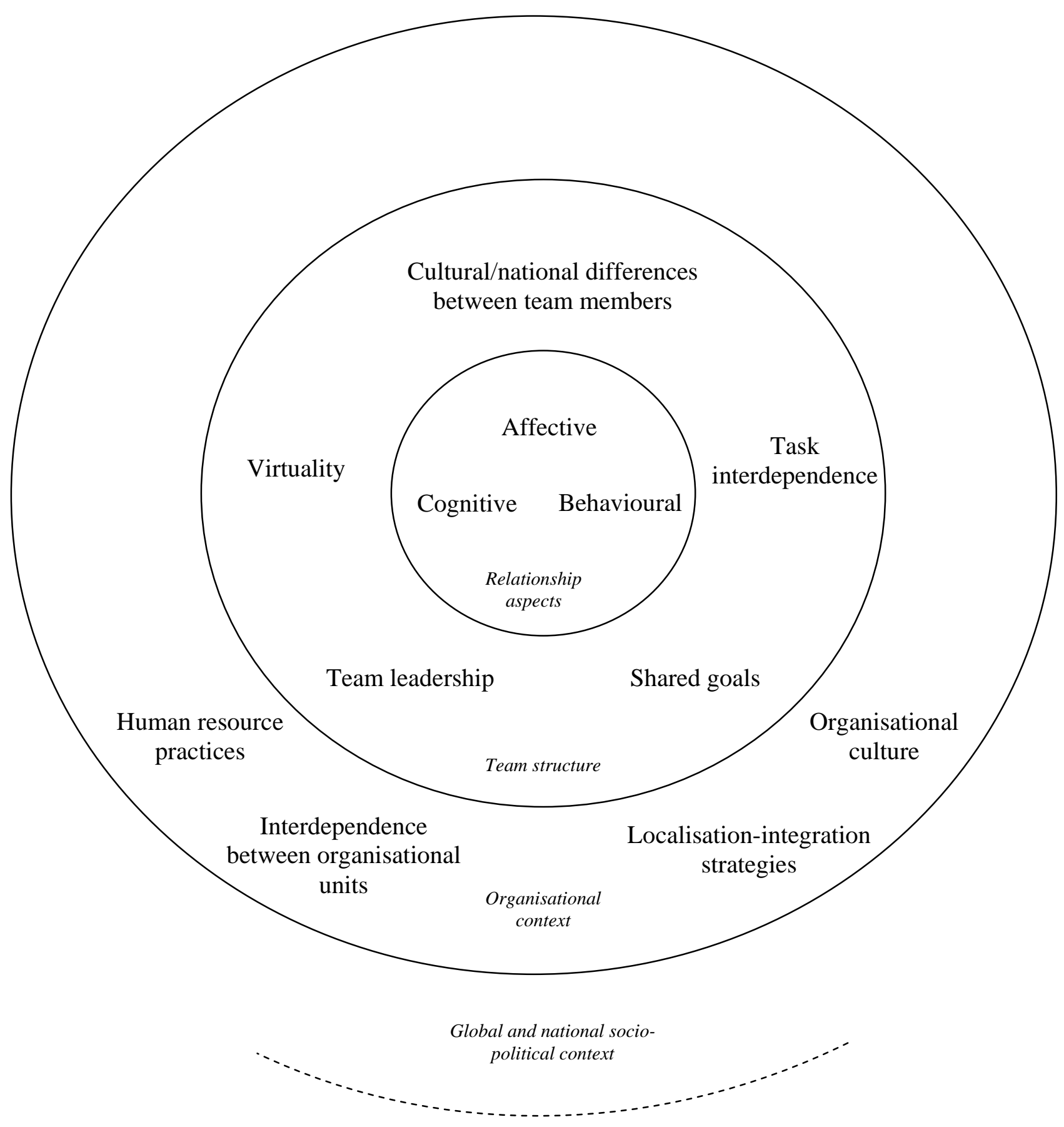


Table 1. Influences between Relationship Aspects as Indicated in the Reviewed Literature

\begin{tabular}{|c|c|c|c|c|c|c|c|c|c|c|c|}
\hline & $\begin{array}{c}\text { Team } \\
\text { identity }\end{array}$ & $\begin{array}{l}\text { Subgroup } \\
\text { formation }\end{array}$ & $\begin{array}{c}\text { Role } \\
\text { expectations }\end{array}$ & $\begin{array}{c}\text { Shared } \\
\text { understanding }\end{array}$ & Trust & Communication & $\begin{array}{l}\text { Knowledge } \\
\text { creation }\end{array}$ & $\begin{array}{c}\text { Contribution } \\
\text { of effort }\end{array}$ & Conflicts & $\begin{array}{c}\text { Interpersonal } \\
\text { affect }\end{array}$ & Satisfaction \\
\hline Team identity & - & & & & & & & & & & \\
\hline $\begin{array}{l}\text { Subgroup } \\
\text { formation }\end{array}$ & A,B & - & & & & & & & & & \\
\hline $\begin{array}{c}\text { Role } \\
\text { expectations }\end{array}$ & & & - & & & & & & & & \\
\hline $\begin{array}{c}\text { Shared } \\
\text { understanding }\end{array}$ & $\mathrm{B}$ & & B & - & & & & & & & \\
\hline Trust & A & A & & A & - & & & & & & \\
\hline Communication & A,B & A & B & A,B & A,B & - & & & & & \\
\hline $\begin{array}{l}\text { Knowledge } \\
\text { creation }\end{array}$ & A & A & & $\mathbf{A , B}$ & $\mathbf{A , B}$ & A & - & & & & \\
\hline $\begin{array}{c}\text { Contribution of } \\
\text { effort }\end{array}$ & A & A & A & $\mathrm{A}$ & $\mathbf{A , B}$ & & A & - & & & \\
\hline Conflicts & A,B & A & A & A,B & $\mathbf{A , B}$ & A,B & B & A & - & & \\
\hline $\begin{array}{c}\text { Interpersonal } \\
\text { affect }\end{array}$ & & A,B & & $\mathrm{A}$ & $\mathbf{A , B}$ & A & & $\mathrm{A}$ & $\mathbf{A , B}$ & - & \\
\hline Satisfaction & & & & A & A & A & $\mathbf{A , B}$ & B & A & & - \\
\hline
\end{tabular}

A: Aspect on the top is reported to influence aspect on the left.

B: Aspect on the left is reported to influence aspect on the top. 
Table 2. Configuration examples

\begin{tabular}{|c|c|c|}
\hline \multicolumn{3}{|c|}{ Configuration 1: Commitment and tight coupling } \\
\hline \multirow{5}{*}{$\begin{array}{l}\text { Factors } \\
\text { Strong cultural differences } \\
\text { High level of virtuality } \\
\text { High task interdependence } \\
\text { Strong integrative leadership } \\
\text { Strong shared goals }\end{array}$} & \multicolumn{2}{|l|}{ Relationship aspects } \\
\hline & Team identity & Strong \\
\hline & Subgroup formation & $\begin{array}{l}\text { Moderate, supports } \\
\text { team learning }\end{array}$ \\
\hline & Role expectations & Highly clear \\
\hline & Shared understanding & High \\
\hline & Trust & High \\
\hline & Communication & Highly effective \\
\hline & $\begin{array}{l}\text { Knowledge creation, } \\
\text { innovation }\end{array}$ & $\begin{array}{l}\text { High across } \\
\text { subgroups }\end{array}$ \\
\hline & Contribution of effort & High \\
\hline & Conflicts & Constructive \\
\hline & Interpersonal affect & Highly developed \\
\hline & Satisfaction & High \\
\hline
\end{tabular}

\begin{tabular}{|c|c|c|}
\hline \multicolumn{3}{|c|}{ Configuration 2: Commitment and loose coupling } \\
\hline Factors & \multicolumn{2}{|l|}{ Relationship aspects } \\
\hline \multirow{11}{*}{$\begin{array}{l}\text { Strong cultural differences } \\
\text { High level of virtuality } \\
\text { Low task interdependence } \\
\text { Weak integrative leadership } \\
\text { Strong shared goals }\end{array}$} & Team identity & Strong \\
\hline & Subgroup formation & $\begin{array}{l}\text { Strong, supports } \\
\text { learning within } \\
\text { organisational } \\
\text { subunits }\end{array}$ \\
\hline & Role expectations & Less clear \\
\hline & Shared understanding & Lower \\
\hline & Trust & Possibly lower \\
\hline & Communication & Sufficiently effective \\
\hline & $\begin{array}{l}\text { Knowledge creation, } \\
\text { innovation }\end{array}$ & $\begin{array}{l}\text { High within local } \\
\text { subunit } \\
\text { Sufficient exchange } \\
\text { between subgroups }\end{array}$ \\
\hline & Contribution of effort & High \\
\hline & Conflicts & Constructive \\
\hline & Interpersonal affect & Less developed \\
\hline & Satisfaction & High \\
\hline
\end{tabular}


Appendix 1. Influence of factors on relationship aspects (suggested by the literature)

\begin{tabular}{|c|c|}
\hline FACTOR & $\begin{array}{l}\text { INFLUENCE ON RELATIONSHIP } \\
\text { ASPECTS }\end{array}$ \\
\hline Cultural differences & $\begin{array}{ll}\text { - } & \text { Team identity } \\
\text { - } & \text { Subgroup formation } \\
\text { - } & \text { Shared understanding } \\
\text { - } & \text { Trust } \\
\text { - } & \text { Communication } \\
\text { - Knowledge creation } \\
\text { - } & \text { Contribution of effort } \\
\text { - } & \text { Conflicts } \\
\text { - Interpersonal affect } \\
\text { - Satisfaction }\end{array}$ \\
\hline Virtuality & $\begin{array}{ll}\text { - } & \text { Team identity } \\
\text { - } & \text { Subgroups } \\
\text { - } & \text { Role expectations } \\
\text { - } & \text { Thared understanding } \\
\text { - } & \text { Communication } \\
\text { - } & \text { Knowledge creation } \\
\text { - } & \text { Contribution of effort } \\
\text { - } & \text { Conflicts } \\
\text { - Interpersonal affect } \\
\text { - } & \text { Satisfaction } \\
\end{array}$ \\
\hline Team leadership & $\begin{array}{ll}\text { - } & \text { Team identity } \\
\text { - } & \text { Subgroups } \\
\text { - } & \text { Role expectations } \\
\text { - } & \text { Shared understanding } \\
\text { - } & \text { Trust } \\
\text { - } & \text { Communication } \\
\text { - } & \text { Contribution of effort } \\
\text { - } & \text { Conflicts }\end{array}$ \\
\hline Shared goals & $\begin{array}{ll}\text { - } & \text { Team identity } \\
\text { - } & \text { Subgroups } \\
\text { - } & \text { Shared understanding } \\
\text { - } & \text { Trust } \\
\text { - } & \text { Communication } \\
\text { - } & \text { Conflicts } \\
\end{array}$ \\
\hline Task interdependence & $\begin{array}{ll}\text { - } & \text { Role expectations } \\
\text { - } & \text { Trust } \\
\text { - } & \text { Knowledge creation } \\
\text { - } & \text { Conflicts } \\
\end{array}$ \\
\hline Interdependence between local subunits & - Communication \\
\hline
\end{tabular}




\begin{tabular}{|c|c|}
\hline & - Knowledge creation \\
\hline Localisation-integration strategies & $\begin{array}{ll}\text { - } & \text { Shared understanding } \\
\text { - } & \text { Communication } \\
\text { - } & \text { Knowledge creation } \\
\text { - } & \text { Contribution of effort } \\
\text { - } & \text { Conflicts }\end{array}$ \\
\hline Organisational culture & $\begin{array}{ll}\text { - } & \text { Shared understanding } \\
\text { - } & \text { Communication } \\
\text { - } & \text { Knowledge creation } \\
\text { - } & \text { Contribution of effort } \\
\text { - } & \text { Conflicts } \\
\end{array}$ \\
\hline Human resource practices & $\begin{array}{ll}\text { - } & \text { Team identity } \\
\text { - } & \text { Shared understanding }\end{array}$ \\
\hline Socio-political context & $\begin{array}{ll}\text { - } & \text { Subgroup formation } \\
\text { - } & \text { Interpersonal affect } \\
\end{array}$ \\
\hline
\end{tabular}

